\title{
Injera (An Ethnic, Traditional Staple Food of Ethiopia): A review on Traditional Practice to Scientific Developments
}

\author{
Satheesh Neela* (D) and Solomon Workneh Fanta
}

\begin{abstract}
Injera is fermented Ethiopian ethnic traditional staple food prepared usually form teff flour [Eragrostis tef (Zucc.) Trotter]. Almost all the Ethiopians consume this food at least once in a day. Injera preparation composed of many steps, starting from grain preparation to baking; these all steps are still performing with indigenous knowledge with traditional practices. This Ethiopian national super food appreciating in many western countries due to the superior nutritional properties, especially lack of gluten and good mineral compositions (Rich of Iron). Research on injera preparation from composite flours for nutritional enhancement and sensory quality improvements were took lion share in reported scientific research. However, limited research was reported on preservation of injera by chemical ingredients and natural species, microbes involved in fermentation and spoilage. In addition, very fewer studies were reported on effect of milling quality of injera seed and role of fermentation on anti-nutritional factors degradation. However, scientific review to show the injera traditional practice and scientific research undertaken in this area is hardly found. In considering above all, this review is under taken with objective to review the traditional ethnic practice and scientific research reported on injera preparation.
\end{abstract}

Keywords: Absit, Composite flour, Ethnic staple food, Ethiopian bread, ersho, Injera, shiro, wot

\section{Introduction}

"Injera" is an Amharic term for Ethiopian bread similar to pan cake, made usually from teff. Injera is thin, prepared from teff flour, water and starter (a fluid collected from previously fermented mix) after successive fermentations [1]. The best acceptable (sensory) injera should be rich in eyes, softer, thin, rolable and sour taste due to the fermentation process [2]. Injera is a traditional common ethnic staple food consumed in all the parts of the Ethiopia and Eretria, some parts of the Somalia [3]. However, small portion of rice, wheat, enset (Ensete ventricosum (Welw.) Cheesman) based foods consumed as part of the staple food along with injera in Ethiopia [4]. Gebrekidan and Gebrehiwot described that distinctive injera is in a circle shape, softer in texture, spongy and resilient, about $6 \mathrm{~mm}$

\footnotetext{
*Correspondence: neela.micro2005@gmail.com

Faculty of Chemical and Food Engineering, Bahir Dar Institute of Technology, Bahir Dar University, Post box Number: 026, Bahir Dar, Ethiopia
}

in thickness, $60 \mathrm{~cm}$ in diameter with uniformly spaced honeycomb-like 'eyes' on the top [5].

Flatten breads/pan cakes with or without fermentation is very famous in diverse areas of the world, they may be differs each in the ingredients and preparation process, size and sensory properties. The foods similar to the injera were available in all over the world, as stated in the previous, their ingredients and processing methods may be different from the injera. Some examples are Dosa (India) [6], Cong You Bing (China), Apam balik (Chains, Taiwan, Brunei, Indonesia, Malaysia and Singapore) [7], Baghrir (Algeria and Morocco) [8], Bánh cu $n$ (Northern Vietnam) [9], Blini (Russia, Ukraine and Belarus) [10], Cachapa (Venezuela) [11], Chatānmari (Nepal) [12], kissra (Sudan) [13].

Teff is an ancient crop belongs to family poaceae, it is very popular in highlands of Ethiopia since more than 2, 000 years. Ethiopia is considered as the place of teff

(c) The Author(s). 2020 Open Access This article is licensed under a Creative Commons Attribution 4.0 International License, which permits use, sharing, adaptation, distribution and reproduction in any medium or format, as long as you give appropriate credit to the original author(s) and the source, provide a link to the Creative Commons licence, and indicate if changes were made. The images or other third party material in this article are included in the article's Creative Commons licence, unless indicated otherwise in a credit line to the material. If material is not included in the article's Creative Commons licence and your intended use is not permitted by statutory regulation or exceeds the permitted use, you will need to obtain permission directly from the copyright holder. To view a copy of this licence, visit http://creativecommons.org/licenses/by/4.0/. 
origin [14] and domestication [15]. Teff was reported extensive distribution in high elevation and rainfall regions of central, eastern and southern Africa. Now, nutritionists considered teff as an ancient and "super grain". Teff cultivation has also reported in some other parts of the world like, USA, South Africa, Australia, India, Kenya, Eritrea, Djibouti, southeastern Sudan and Netherlands [16].

Teff appreciated for balanced nutrition properties, reported to possess protein in the range of $9.4-13.3 \%$ by superior equilibrium in essential amino acids like leucine, valine, proline, alanine, glutamic and aspartic acids are the major. In case of the carbohydrates, $73 \%$ of starch present in whole kernel stored as multilateral starch granules in the endosperm of the grain [15]. Teff reported $2.6-3.0 \%$ of ash, and $2.0-3.1 \%$ of lipid $[15,17]$ with rich amounts of minerals like Iron, Calcium, Zinc, Magnesium than other cereals [18]. The nutritional composition of the Teff and teff injera from USDA data base is presented in Table $1[19,20]$

In certain aspects, teff injera was considered greater to wheat bread and has possible nutritional importance. Teff is the most well-liked grain for preparation of injera, even though additional grains such as sorghum, maize, barley, wheat and finger millets reported to use occasionally. Usually, injera is consumed along with the stew called as "wot" [21]. The term wot meaning is 'wet' in Amharic language, the resemblance English meaning is a stew. The stew is made from vegetables and animal meat and served with injera. "Doro-wot" is a stew prepared from chicken, onions, red pepper, spices, butter and water. "Shiro" is a most common wot prepared from lentils, pulses, spices, red pepper etc [22]. However, injera also consumes commonly with cooked meat, boiled vegetables like beat root, cabbage, potato, spinach, kale, etc. The honey-comb like eyes help in the grasping of wot which soaks into the pores on the surface of injera [23].

In Ethiopia still the injera preparation and consumption carrying by traditional practices only. However, scientific research on areas like injera from composite flour; microbiological properties and preservation were reported. In this regards, the objective of this paper is to review the traditional practice and scientific research related to the injera preparation.

\section{History, cultural and Ethnic Aspects of Injera}

According to the Stewart and Getachew [1], the history of injera preparation is a mistery, however, they reported that from unpublished sources injera dated back to the 100 B.C. In case of the teff grain, the history was dated back to the $3350 \mathrm{BC}$, archeologists reported the presence of teff grain in Egypt pyramids [24]. However, some authors are reported the evidence of excavated cooking pans of injera and "shiro" (a stew with lentils) (Fig. 2 A) dated back to the $600 \mathrm{AD}$ [25].

Ethiopians have special beliefs and attitudes towards to the foods in this regard; injera's role in Ethiopian culture is significant and prestigious. In Ethiopia, people always celebrate national and religious holidays including their family gatherings like marriage, birthday, and death ceremonies. In all the situations injera makes majority of the food in lunch and dinner times. However, the dried injera is reconstituted in to a spicy, usually vegan diet constitutes of garlic and tomato sauce consumed in breakfast called as "firfir". Injera usually consumes with "wot", it is a traditional dish made from the mix of vegetables, meat, different spices and sauces. Usually, "wot" served on the top of the injera. Ethiopian Orthodox Christians follows the fasting in different months in the holidays like Easter and Christmas. At these fasting days they strictly follows the vegan diet, at this duration injera consumes with wot prepared by the lentils called as "shiro" along with different boiled vegetables and pasta (Fig. 2 E) served on a beautiful basket called as "mesob". In addition, injera is still a major diet for migrant Ethiopians to different western countries. This is evident from the availability of the Ethiopian restaurants and injera in western countries where Ethiopian migrant's populations are more.

Traditionally meal (injera) in Ethiopia consumed in the communal plate (known 2-3 people eats in one plate with same injera) it shows their relation, closeness and friendship. Amhara people in Bahir Dar region (Fig. 1) have a strong belief that, the woman who prepares the best quality of the injera is considered as good at domestic management. Similarly, the women who prepared injera with good eyes compared with honey bee and denote that, she is very hard working in nature. Also, injera has unique role in baptism ceremony of the new born child in orthodox Christians in Bahir dar city. In this ceremony some families practice roiling of baby in injera and they believe that, this act provides bright future and good fortune for the children. In addition, the orthodox churches the priest consumes injera after finishing the prayers, before leaving the church which is provided by the group of church members and these members feel this activity as a devotional. In Amhara region, elders gift injera to younger and blessed to have great fortune.

Similarly, in marriage, birth ceremonies near and dear gusts bring injera to the host and considering that this provides good feature. In case of the death ceremonies, people take injera in mesob to support the family of the death person (Fig. 2 F). Few groups in the Amhara region believe that if a person's dreams injera consumption in sleep considered as a good sign for the future. In Ethiopia graduation ceremony is having a special role in 
Table 1: Nutritional composition of Teff injera and Teff grain (red) per $100 \mathrm{~g}$

\begin{tabular}{|c|c|c|c|}
\hline Name of the component & Unit & Teff Injera & Teff grain \\
\hline Water & g & 76.02 & 8.82 \\
\hline Energy & kcal & 88 & 367 \\
\hline Protein & g & 3.48 & 2.38 \\
\hline Total Fat & g & 0.83 & 2.37 \\
\hline${ }^{a}$ Carbohydrate & g & 18.31 & 73.13 \\
\hline Total dietary Fiber & g & 2.7 & 8 \\
\hline Starch & g & NR & 36.56 \\
\hline \multicolumn{4}{|l|}{ Minerals } \\
\hline Calcium & $\mathrm{mg}$ & 13 & 180 \\
\hline Iron & $\mathrm{mg}$ & 1.03 & 7.63 \\
\hline Magnesium & $\mathrm{mg}$ & 64 & 184 \\
\hline Phosphorus & $\mathrm{mg}$ & 89 & 429 \\
\hline Potassium & $\mathrm{mg}$ & 152 & 427 \\
\hline Sodium & $\mathrm{mg}$ & 229 & 12 \\
\hline Zinc & $\mathrm{mg}$ & 0.85 & 3.63 \\
\hline Copper & $\mathrm{mg}$ & 0.14 & 0.81 \\
\hline Manganese & $\mathrm{mg}$ & NR & 9.24 \\
\hline Selenium & $\mu \mathrm{g}$ & 1.5 & 4.4 \\
\hline \multicolumn{4}{|l|}{ Vitamins } \\
\hline Thiamin & $\mathrm{mg}$ & 0.174 & 0.39 \\
\hline Riboflavin & $\mathrm{mg}$ & 0.076 & 0.27 \\
\hline Niacin & $\mathrm{mg}$ & 1.711 & 3.363 \\
\hline Pantothenic acid & $\mathrm{mg}$ & NR & 0.942 \\
\hline Vitamin B6 & $\mathrm{mg}$ & 0.143 & 0.482 \\
\hline Total Folate & $\mu \mathrm{g}$ & 29 & NR \\
\hline Lutein + zeaxanthin & $\mu \mathrm{g}$ & 49 & 66 \\
\hline bVitamin E & $\mathrm{mg}$ & 0.08 & 0.08 \\
\hline Vitamin $\mathrm{K}$ & $\mu \mathrm{g}$ & 1.7 & 1.9 \\
\hline \multicolumn{4}{|l|}{ Fatty acids } \\
\hline Total saturated Fatty acids & g & 0.177 & 0.449 \\
\hline Total monounsaturated Fatty acids & g & 0.272 & 0.589 \\
\hline Total polyunsaturated Fatty acids & g & 0.236 & 1.071 \\
\hline \multicolumn{4}{|l|}{ Amino acids } \\
\hline Tryptophan & g & NR & 0.139 \\
\hline Threonine & g & NR & 0.51 \\
\hline Isoleucine & g & NR & 0.501 \\
\hline Leucine & g & NR & 1.068 \\
\hline Lysine & g & NR & 0.376 \\
\hline Methionine & g & NR & 0.428 \\
\hline Cystine & g & NR & 0.236 \\
\hline Phenylalanine & g & NR & 0.698 \\
\hline Tyrosine & g & NR & 0.458 \\
\hline Valine & g & NR & 0.686 \\
\hline Arginine & g & NR & 0.517 \\
\hline
\end{tabular}


Table 1: Nutritional composition of Teff injera and Teff grain (red) per $100 \mathrm{~g}$ (Continued)

\begin{tabular}{llll}
\hline Name of the component & Unit & Teff Injera & Teff grain \\
\hline Histidine & $g$ & NR & 0.301 \\
Alanine & $g$ & NR & 0.747 \\
Aspartic acid & $g$ & NR & 0.82 \\
Glutamic acid & $\mathrm{g}$ & NR & 3.349 \\
Glycine & $\mathrm{g}$ & NR & 0.477 \\
Proline & $\mathrm{g}$ & NR & 0.664 \\
Serine & $\mathrm{g}$ & NR & 0.622 \\
\hline
\end{tabular}

Source: USDA Food data base $[19,20]$

$\mathrm{NR}=$ Not reported

a Calculated by difference method

${ }^{b}$ Alpha-tocopherol

celebrations. Guests bring injera to the graduate along with the traditional beverages like "Talla", "Arake" and all people celebrate the host's graduation. Similarly, Ethiopian coffee ceremony is the very famous and celebrates in different holidays, in this ceremony injera used to distribute to the gust along with the coffee.

Particularly, in the rural areas the agriculture activities like harvesting and post harvest processing are shared by neighbors or small community. The person used the service of the neighbors in these activities at the time of meal serves injera with different traditional drinks as the token of love and thankfulness. In all such cases there is no wages for the work. A mesob (a injera placing basket) is printed on the 10 bir note (Ethiopian currency), it shows the importance of injera in Ethiopian culture as a national food (Fig. 2 C, D).

\section{Traditional practices in Injera preparation}

The ratio of the teff and different other grains in the injera depends on the traditional practices, previous experience, family financial status and family practices. Teff is a major cereal and millets, barley, wheat, sorghum, maize are reported to use in different

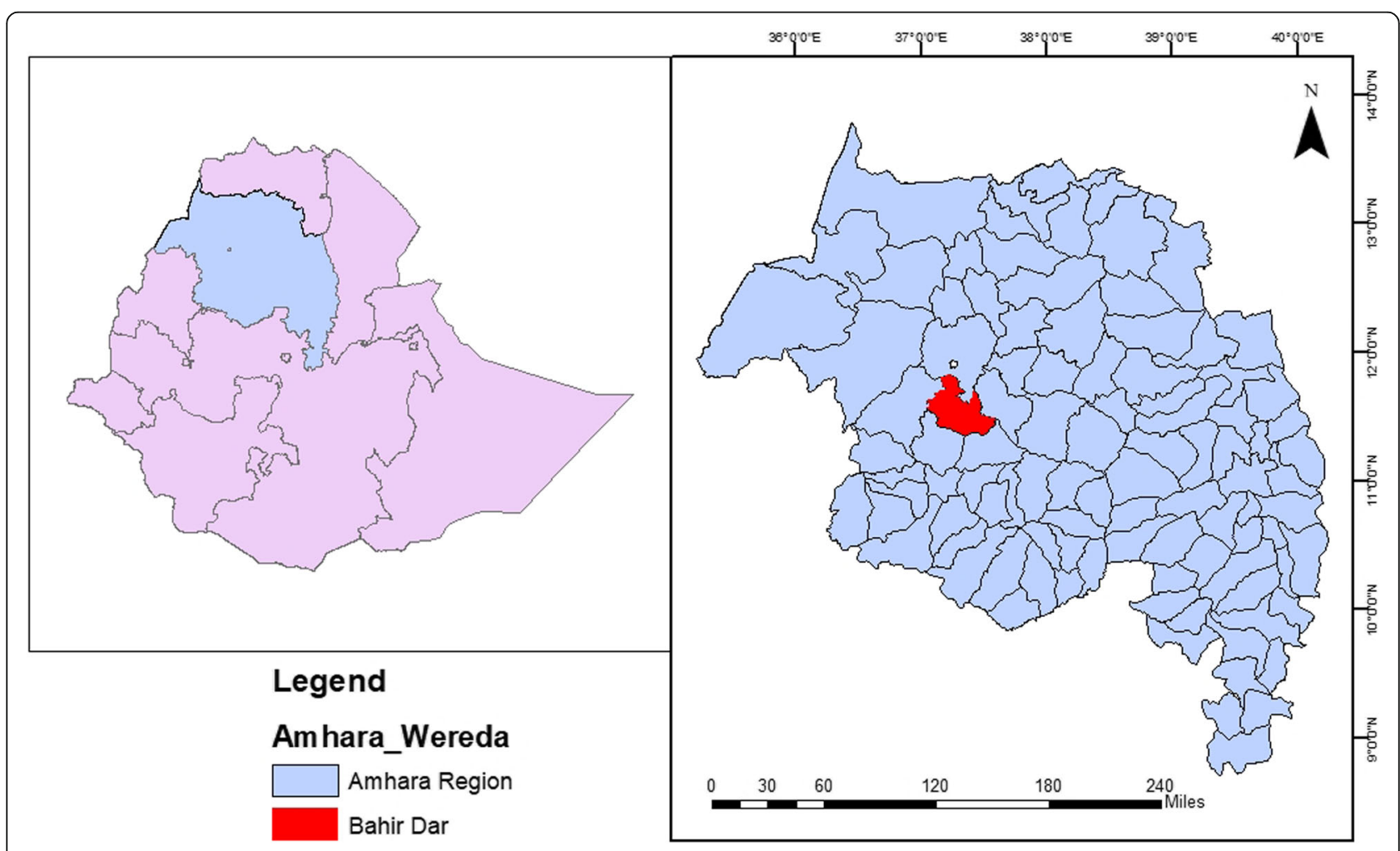

Fig. 1 The Map of the Bahir dar city in Amhara region, Ethiopia 


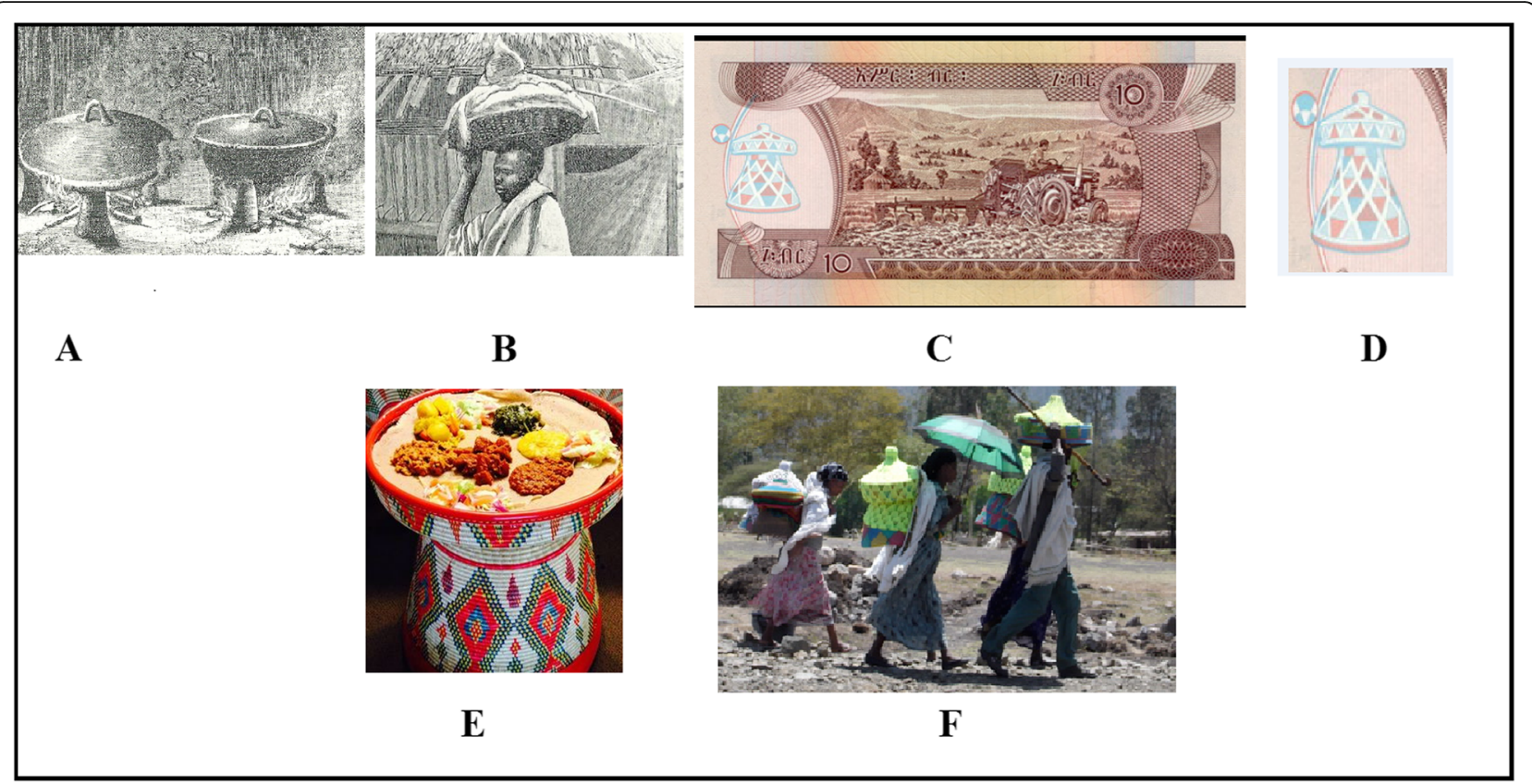

Fig. 2 Some of the pictures showed the historical evidences and the traditional practice of injera in Ethiopia. A. Injera cooking in a mitad (left) and spicy wot cooking in a clay pot from the findings of an early 1970s excavation of Aksumite mitads, placing them in the late fifth or sixth centuries, thus some time before 600 AD (Source: Harry Kloman 2013, [25]); B. Ethiopian carnying injera in mesob on his head (Source: Harry Kloman 2013, [25]); C \& D. The Ethiopian currency 10 birr note printed with misob, a traditional injera serving basket handmade with specific grass and threads; E. Injera placed on the the beautiful messob served with different; F. This is the image shows that the near and dear carrying the injera in misob to a funeral happening in the next village (Marian 2011, [26])

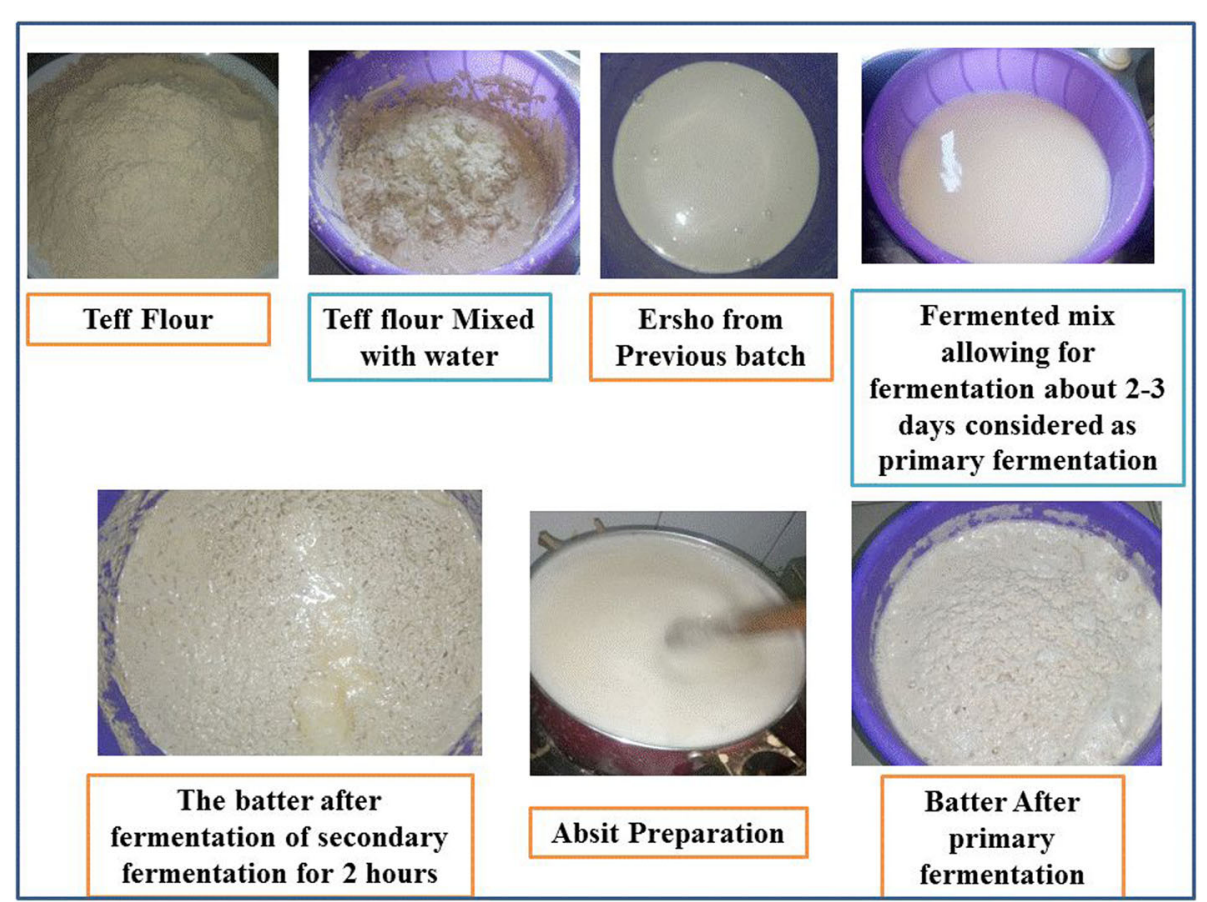

Fig. 3 The traditional teff flour fermentation process for injera preparation. The traditional fermentation of the teff flour is very important for the preparation of the injera. In the process, the teff flour is mixed with the water and a seed culture (Ersho) from the previous batch. The mixture will be fermented from 2-3 days for primary fermentation. After the primary fermentation a portion of the batter mixed and boiled to produce absit. The prepared absit mixes back to the primary fermented batter and allowed for secondary fermentation for 2 hours. Finally batter is ready for injera preparations 
proportions. The traditional preparation of injera batter was presented in Fig. 3. Depending on the requirements, grains used to prepare by removing the inferior quality grains and dust like chuff and other unwanted materials. Further, all the cereals used to converts into flour by the commercial mills (disc mills are the commonly used). It is a practice to mix one part of flour with two parts of water and about $16 \%$ "ersho" by weight of the flour [22, $27,28]$. The container used to mix the components called as "bohaka" which made of clay, metal or wooden container. The flour, water and ersho are meticulously mixed by hand stirring to form a thin, watery paste and left for primary fermentation around 30 to 72 hours [28]. However, the fermentation time depends on the altitude (which determines the temperature) of the area, the concentration of the ersho and the type of the container used [27]. Scientific study reported that, ersho contained $96.4 \%$ moisture, $0.05 \mathrm{mg}$ riboflavin/100 g, and $0.4 \mathrm{mg}$ of niacin/ $100 \mathrm{~g}$ [29]. Ashenafi reported the $\mathrm{pH}$ of ersho samples was about 3.5 and titratable acidity was ranged among $3.1 \%-5.7 \%$ [30].

Some researchers used varying amounts of teff flour to water ratio in teff flour fermentation. The flour to water ratio varies in literature from 1:1 to 2:3. The flour: water ratio of 1:1 was used by Abraha, et al., (2013) [31], 1:2 was used by Ashagrie and Abate, (2012) [28], Girma et al., (2013) [27] and Abiyu et al., (2013) [32] , while a ratio of 2:3 was used by Zegeye (1997) [22], 1:1.6 was used by Girma et al., (1989) and Mary et al., (1989) [33, 34]. The time for ceases finest fermentation considered by the gas formation and the dough and small portion of the liquid phase separation on the surface [1]. Time required for the fermentation effected by diverse factors like, microbial flora of ersho and flour, fermentation temperature and the cleanliness of the container used. After about 48 to 72 hours of primary fermentation, fraction of the fermented mix is gelatinized by cooking to form "absit" which usually used to added back to the fermentation batter (in primary fermentation), this step initiates the 'secondary fermentation'. Mihrete, (2019) [35], Zegeye, (1997) [22], Desiye et al., (2017) [36], Wendy Darling Attuquayefio, (2014) [23], Beruk and Fasil (2017) [37], Ronda, (2019) [38] used 10\% of Absit in their research studies. However, there is a difference in the water ratio and time and cooking temperature used for preparation of absit. In contrast, few studies like Chemeda \& Bussa, (2018) used $200 \mathrm{ml}$ of the fermented mixture was added with $400 \mathrm{ml}$ of water and brought to boiled and added back to $1 \mathrm{~kg}$ of original flour [39]. Finally, the most of the researchers concluded that, absit is a gruel work as a dough binder in the course of secondary fermentation of dough.

After cooling back to about $46^{\circ} \mathrm{C}$, absit reported to be mixed into fermenting vat for the second phase of fermentation which allowed for about $2 \mathrm{~h}$. After adding, absit develops the gas formation and causes the paste to rise [40]. Adding absit is also critical to develop the desired texture and consistency, as injera made without absit tends to be powdery and have fewer eyes which are not liked by Ethiopian consumers. It is conformed that, teff, millet, and corn are the only grains that require absit during the process of making injera [29]. Finally, researchers reported that absit has a significant influence on the physico-chemical and sensory quality of injera.

Once fermented batter is ready after the successful primary and secondary fermentations, injera griddled by pouring about two-third liter of the batter onto the hot greased plate known as "metad" (injera griddle made of clay) using circular movement from the peripheries to the center (Fig. $4 \mathrm{C}, \mathrm{D}$ ), by closing a lid known as "kidan" (Fig. 4E). For this poring process a special plastic device used known as "Mazoria" (Fig. 4 A). It was reported that, injera cooks about 2-3 minutes at metad temperature of $90-95{ }^{\circ} \mathrm{C}$ [41]. Rapeseed oil is a common lubricant used to grease the metad between each injera baking. Several layers of injera traditionally stored in a 'messob' (traditional straw basket) (Fig. 4 H, I) with tight packing in polythene cover. It is a traditional practice for preservation of injera for three days in a cool, dry and ventilated place.

\section{Scientific Research on Injera}

Limited research was reported on the major areas of injera preparation. One of the well studied parts was development of injera from composite flours for the improved nutritional and sensory quality. In contrast, limited research reported on microbial characterization of the fermented batter, preservation of injera, degradation of the anti-nutritional factors and effect of processing methods on quality of the injera. However, research on the energy requirements, development of the injera cooking pans were developed and reported well. Moreover, a well reviewed document on the injera baking technologies was published by Adem and Ambie (2017) [42]. The following sections are composed of the research reported on the scientific research done on different aspects of injera.

\section{Scientific studies reported on Composite flours for injera}

As the injera preparation usually only from the cereals, nutritionists are evaluated injera is limited in protein and rich with anti-nutritional factors like tannins. However, due to the high price of the teff, preparations of the injera with the other low cost alternatives were investigated. Some researchers were investigated the affects of functional ingredients like fenugreek and flaxseed on injera nutritional and sensory quality. 


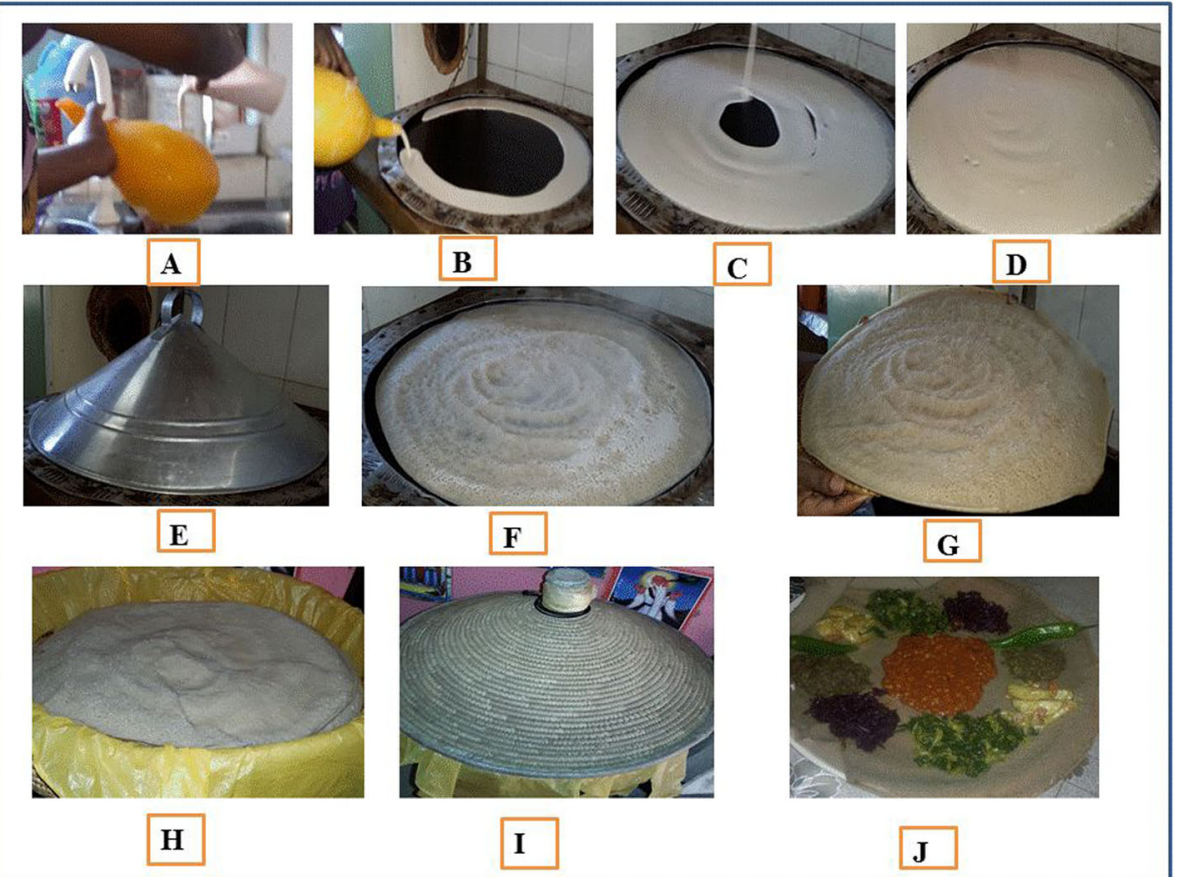

Fig. 4 The baking process of the injera. The properly fermented batter is very important for the preparation of injera. After the secondary fermentation the batter filled to the pouring device called as "Mazoria" The batter will be poured on hot baking pan called as "Metad" from outer part to inner and covered with a lid called as "Kidan". The injera after cooked enough it will remove from the pan and packed "Measob". Usually, injera will be preserved for 3 days. A. Fermented batter filling in to pouring device known as "Mazoria"; B. Pouring the injera batter on to hot baking pan known as "Metad" from periphery to center; C, D. Pouring the batter on to the "Metad"; E. Covering with the lid at the time of baking known as "Kidan"; F. Baked injera ready to remove from the pan; G. Baked injera removed from "Metad"; H, I. Packing the injera in polythene sheet to pack in to "Mesob" (a traditional storage made with hard grass); J. Injera served with different boiled vegetables and stew

Lamesgen Yegrem, (2019) was conducted a recent study to investigate the effect of lupine flour (Australian sweet lupine and Ethiopian Dibettered lupine seed) blending ratios on physico-chemical quality and sensory acceptability of injera. In this study reported that the crude protein content highly increased (11.78 to 18.84 $\%)$ as the proportion of lupines increased. Iron, zinc and calcium contents were reported higher than injera without the lupine flours. Sensory acceptability of blended injera was reduced after lupine ratio was increased above $10 \%$. Rollability and eye distribution were reported higher for composite injera from dibettered lupine rather than Australian sweet lupine [43]. Whereas, Woldemariam et al., (2019) evaluated amaranths (0-60\%), teff (40$100 \%)$, barley $(0-20 \%)$ flour combinations on nutritional and sensory adequacy of injera. Protein and gross energy, calcium, iron and zinc contents were reported to increase as the rise in amaranth flour concentration and addition of barley reported rise in the carbohydrate of injera. Overall optimum concentration with protein (11.84-14.60\%), carbohydrate (74.39-79.71\%), Energy (363.68-381.22 kcal/100 g), Fe (29.34-42.44 mg/100 g), and $\mathrm{Ca}(177.42-430.47 \mathrm{mg} / 100 \mathrm{~g})$ of injera was reported in a range of $40-77.5 \%$ teff, $12.5-60 \%$ amaranths and $0-$
$10 \%$ barley. However, sensory adequacy was reported to decrease with rise in the proportion of amaranths and barley. The overall optimum point was reported in a range of Amaranth of $12.5-60 \%$, Barely of $0-10 \%$ and teff of $40-77.5 \%$. Finally, concluded that blending of teff, amaranths, and barley flours can improve the proximate and mineral composition of injera [44].

Mihrete, (2019) determined effect of the faba bean (5$15 \%)$, sorghum (20-30\%) and teff (55-70\%) flour combinations and fermentation time (24, 48 and $72 \mathrm{~h}$ ) on mineral contents and sensory quality of injera. High concentration of Fe $(22.66 \mathrm{mg} / 100 \mathrm{~g}), \mathrm{Zn}(23.81 \mathrm{mg} / 100$ g) and $\mathrm{Ca}(187.25 \mathrm{mg} / 100 \mathrm{~g})$ contents were reported in injera prepared with $55 \%$ teff, $30 \%$ sorghum and $15 \%$ faba bean, fermented for $72 \mathrm{~h}$. Sensory adequacy of injera scored a mean rating well above the average acceptability. Finally, Mihrete, (2019) reported that, most favored injera by assessors was teff flour combined with $20 \%$ sorghum and $10 \%$ faba bean flours fermented for 72 h [35].

Daka et al., (2019) evaluated the effect of fenugreek (roasted, germinated and raw) on phyto-chemical contents and antioxidant capacity of teff injera. The maximum total flavonoid content $(117.4 \mathrm{mg} / \mathrm{g})$ and total 
condensed tannin content $(18.44 \mathrm{mg} / \mathrm{g})$ were reported in injera prepared with 5\% roasted and 5\% raw fenugreek. The 5\% roasted fenugreek substituted injera showed strongest anti-oxidant properties than control. Finally, researchers concluded the substitution of processed fenugreek flour with teff flour reported enhancement in antioxidant ability and total flavonoid composition than raw fenugreek flour added injera [45]. In addition, Daka et al., (2019) determined the effect 5\% germinated fenugreek substitution on injera in other study. Similarly, results showed the highest crude protein $(15.90 \%)$, crude fiber $(3.42 \%)$ and ash $(2.86 \%)$ crude fat content $(11.90$ $\%)$ for the injera prepared with 5\% raw fenugreeksubstituted. 5\% roasted fenugreek-substituted injera had reported the highest $\mathrm{Ca}(168.7 \mathrm{mg} / 100 \mathrm{~g}), \mathrm{Mg}(16.3 \mathrm{mg} /$ $100 \mathrm{~g}), \mathrm{Zn}(2.0 \mathrm{mg} / 100 \mathrm{~g})$ and $\mathrm{Fe}(2.45 \mathrm{mg} / 100 \mathrm{~g})$. Injera with $1 \%$ fenugreek rated as more overall sensory acceptable than that of $5 \%$ [46].

Tamene et al., (2019) assessed the total folate contents of teff flour, fermented batter and injera by microbial assays using Lactobacillus rhamnosus (ATCC 7469). Folate content of teff flour was determined as $8.7 \mu \mathrm{g} / 100 \mathrm{~g}$ and reported as similar with oats (Consider as folate rich cereals), however injera reported as $14.3 \mu \mathrm{g} / 100 \mathrm{~g}$. Researchers were reported as the increase in folate content and showed high variability (60-148\%). Cooking process of injera reported loss $(52.8 \%)$ in the folate content. In this research they concluded that injera fermentation reported to augmented folate retention raged as 38.0 and $121.8 \%$ [47].

Similarly, Chemeda \& Bussa, (2018) evaluated the effect of amaranth grain addition on injera quality. From this research injera reported that, amaranths grain addition had developed more accepted colour, consistently dispersed eyes, non-sticky and soft surface [39]. In other study, Cherie et al., (2018) reported the optimization study of injera made from blends of teff $(70-100 \%)$, maize $(0-30 \%)$ and rice $(0-30 \%)$. In this study reported that, minerals $(\mathrm{mg} / 100 \mathrm{~g})$ in injera varied from Iron: 17.7 to 25.1 Zinc: $1.62-2.10$, and Calcium: 25.9 to 51.1. Sensory acceptability of color, taste, texture, number of eyes, eye size, eye distribution, top \& bottom surface and overall acceptability were reported superior for injera from blends. Optimum compositions for the injera with the best acceptable color, overall sensory acceptability reported as $70 \%$ teff, $0 \%$ maize and 30\% rice with a desirability of 0.909 [48].

For the first time, Agza, et al., (2018) reported the quinoa flour substitution in injera preparation. The overall essential amino acid profile of the teff and quinoa injera considered as well-balanced. Quinoa replacement from 0 to $40 \%$, reported the protein, fat, fiber and ash contents of the injera was increased. In case of sensory attributes for taste, aroma, rollability, eyes evenness, underneath color and overall acceptability had shown decreasing by increasing the quinoa compositions. Finally, in this research concluded that up to $30 \%$ quinoa flour can incorporate to teff flour with good nutritional profiles without adverse effect on sensory attributes of teffquinoa injera [49].

Abraha \& Abay (2017) evaluated the sensory properties of injera made from combination of diverse cereals (Teff, barley, sorghum and maize) in the proportion of $100,75,50$ and $25 \%$. The outcome of their research revealed that cereal flour blends in injera reported the non significant variation in texture, mouth feel, and overall acceptability, colour, taste and the appearance of injera surface eyes. From this study results concluded that, quality of injera prepared with teff and other cereals ranked next to merely teff [50].

Beruk and Fasil, (2017) determined the effect of blending ratio of cassava (up to $30 \%$ ) on nutritional, physicochemical property and sensory adequacy of injera. Cassava addition reported to significantly reduce all macro nutrients except carbohydrate. From this study outcome reported that, all sensory attributes were significantly affected due to increased cassava flour except color. Increasing the amount of cassava improved the water absorption capacity [37].

Ghebrehiwot et al., (2016) determined the adequacy of injera prepared by grains of a closely related but underutilized grass, Eragrostis curvula (Schrad) and 0, 5, 10\% of sorghum flour. Nutritional profile of E. curvula was reported twice the amount of crude protein than teff. $E$. curvula also contains fat, fiber and minerals better than teff. Injera made of teff and E. curvula flours showed non-significant differences in taste, texture, appearance and overall acceptability. This study suggested that $E$. curvula has the potential to serve as a novel source of gluten-free flour for human consumption. Agronomical reports suggested that cultivation of $E$. curvula is more advantageous among the small scale farmers on marginal lands due to the capability of harvest seeds twice a year (unlike teff) and tolerance to the acidic soils (better than teff) [51].

Abera et al., (2016) prepared injera by incorporation of taro flour (Colocasia esculenta) in to teff flour. Results were reported that, sensory properties of injera were reported lower with the rise in taro levels. The proximate composition of the injera reported that, moisture content, protein, crude fiber, fat and carbohydrate was reported not statically differences. In contrast, ash content showed a significance difference. The optimum point for sensory and proximate composition for injera preparation was 15:85 for taro and teff, respectively [52].

Girma, et al., (2013) reported the effect of teff flour mix with flaxseed on mineral content, antioxidant activity, phytic acid content and microbial quality of injera. 
The results were reported that, functional character enhanced by substitution with whole flaxseed and flour of flaxseed and 3\%, 6\% and 9\% flaxseed incorporation levels. Injera with whole and powdered flaxseed showed a significant effect on minerals, antioxidant properties, phytic acid and microbial quality of injera. From this study reported that, 9\% flaxseed substitution increased the antioxidant power, Zinc and Calcium contents. In contrast phytic acid and Iron contents were deceased as compared to the control [27]. Similarly, Girma, et al., (2013) in other study reported flaxseed incorporation had a considered impact on moisture, fiber, titratable acidity, $\mathrm{pH}$ of the injera. The flaxseed-substituted injera sensory attributes were reported statistically significant different with control. Rise in flaxseed levels reported the increase in sensory scores for rollability, sourness, odour, flavour and overall acceptability, in contrast, colour, injera eyes and underneath colour scores decreased. Finally, reported that, 9\% whole flaxseed flour partial replacement of teff flour had showed improvement in nutritional composition and functional properties includes the dietary fiber, $\omega-3$ fatty acid, proteins, lignans and antioxidant proportion [2].

Abraha et al., (2013) investigated the differences in injera quality by addition of different variety of barley and teff. Significant variation in sensory quality were reported for two barley varieties (Haftusene and Himblil 2011) [31].

Mohammed, et al., (2011) was carried the research to evaluate nutritional value of sorghum flour incorporation in injera. From this research revealed that injera with sorghum flour posses lower protein, ash and fat contents but high in fiber content. Moreover, injera was found to have significantly higher in energy (389.08 $\mathrm{Kcal} / 100 \mathrm{~g}$ ) lower in anti-nutritional factors. Injera with sorghum flour reported with appreciable amount of amino acids except Arginine and Tyrosine [53].

Yetneberk, et al., (2004) studied the effects of 12 sorghum cultivar on injera quality. Form this study they concluded that sorghum cultivar type was significantly affects injera making quality. Cultivars like AW (floury endosperm), 3443-2-op and 76TI \#23 (intermediate), and PGRC/E \#69349 (with more vitreous endosperm) were generally associated with soft, rollable and fluffy positive attributes of injera [54].

Zewdie, et al., (1997) prepared injera by cofermentation of kocho, a product from the false banana with barley to determine its nutrient composition and the microorganisms involved in the fermentation process. The co-fermentation of kocho with barley increased the protein content of the fermented injera by 2.6-fold. The injera prepared from co-fermented dough of kocho and barley was found to be acceptable to
Ethiopian consumers and had very good keeping qualities [55]..

Cherinet, (1993) prepared a composite flour with inexpensive cereal grains for making injera. Sixty four combinations were baked; their physical characteristics and shelf-life properties were tested. The best composition was determined as teff (35\%), wheat (25\%) and sorghum (40\%) for the best sensorial properties. The authors are reported that, $27 \%$ of the cost reduction was reported in the injera by the prepared composites [56].

From the research reported on the composite flour cleared that, type of the composition, quantity affected on the injera physical, sensory and compositional properties as the composition and quantities are varied.

\section{Studies reported on the microbiology of injera fermentation}

Tadesse et al., (2019) reported yeast is responsible for injera fermentation also they identified Pichia fermentans, Pichia occidentalis, Candida humilis, Saccharomyces cerevisiae, and Kazachstania bulderi species in fermented injera batter. This study has confirmed the presence of different yeast species in the fermented mix and conformed the complex nature of injera dough fermentation [57]. Desiye \& Abegaz, (2013) reported the microbial composition of 34 injera batter samples, and identified 107 lactic acid bacteria strains (LAB) and 68 yeast strains were isolated and identified. The LAB strains were identified was Pediococcus pentosaceus (49.53\%), Lactobacillus fermentum (28.04\%), Lactococcus piscium (5.61\%), Lactococcus plantarum (4.67\%), Pediococcus acidilactici (3.74\%), Leuconostoc mesenteroides subsp. mesenteriodes (2.80\%), Lactococcus raffinolactis (2.80\%), L. mesenteriodes subsp. dextranicum (1.87\%), Enterococcus cassiiflavus (0.93\%), and the yeast strains comprised Saccharomyces cerevisiae (48.53\%), Candida humilis (22.06\%), Candida tropicalis (17.65\%), Saccharomyces exiguus (7.35\%) and Pichia norvegensis (4.4\%) [58].

Desiye et al., (2017) collected 34 batter samples and reported the total aerobic mesophilic count, Lactic acid bacteria and yeast increased by about 3 log cycles until $48 \mathrm{hr}$ fermentation, while reported the decrease of $\mathrm{En}$ terobacteriaceae below detectable levels after $18 \mathrm{hr}$ due to the low $\mathrm{pH}$ of the teff batter [36], this trend was reported by Fischer et al., (2014). In their study isolated 76 isolates from 13 different fermenting teff batters. Enterococci and Enterobacteriaceae were below the detection limits of $2 \log \mathrm{cfu} / \mathrm{g}$. Spore forming Bacillus species, yeast and mold counts were detected infrequently and considered as below detection limits. Aerobic mesophiles were reported in wide range of 3 to $7 \log$ after $24 \mathrm{~h}$ incubation and increased up to $8 \mathrm{log} \mathrm{cfu} / \mathrm{g}$ after $72 \mathrm{~h}$ of fermentation. The highest counts were observed for presumptive lactic acid bacteria on average $8 \log \mathrm{cfu} / \mathrm{g}$, 
ranging from 4 to $8 \log \mathrm{cfu} / \mathrm{g}$. These microorganisms include, Lactobacillus brevis, Lactobacillus buchneri, Lactobacillus casei, Lactobacillus fermentum, Lactobacillus plantarum, Pediococcus pentosaceus [59]

Ashenafi, (1994) reported that ersho samples $\mathrm{pH}$ was about 3.5 and titratable acidity was ranged between $3.1 \%$ and $5.7 \%$. The mean aerobic mesophilic counts from four households varied between $6.9 \times$ $10^{6}$ and $1.3 \times 10^{5} \mathrm{cfu} / \mathrm{ml}$ and the aerobic bacterial flora consisted of Bacillus spp. Mean yeast counts ranged between $5.2 \times 10^{5}$ and $1.8 \times 10^{6} \mathrm{cfu} / \mathrm{ml}$ and comprised, in order of abundance, Candida milleri, Rhodotorula mucilaginosa, Kluyveromyces marxianus, Pichia naganishii and Debaromyces hansenii. Candida milleri was reported as the most dominant isolate in all samples. About $90 \%$ of the teff batter samples reported for aerobic mesophilic counts $\sim 10^{5} \mathrm{cfu} / \mathrm{g}$ and Gram-positive bacteria constituted about $71 \%$ of the total isolates. About $80 \%$ of samples had Enterobacteriaceae counts of $10^{4} \mathrm{cfu} / \mathrm{g}$ [30]. Zewdie, et al., (1997) reported that the predominant organisms identified were Lactobacillus, Bacillus and Yeasts. The fermentation process was characterized by the fall in $\mathrm{pH}$ from 5.0 to 4.2 and rise in the titratable acidity from 0.20 to $0.50 \%$ during $96 \mathrm{hrs}$ of fermentation [55].

Gashe determined the involvement of LAB in the fermentation of injera batter, reported as Enterobacteriaceae initiates the fermentation and actions during the first $18 \mathrm{hr}$ of fermentation reduce the $\mathrm{pH}$ of the dough to 5.8. In next stage identified the role of Leuconostoc mesenteroides and Streptococcus faecalis and observed the further reduction in $\mathrm{pH}$ to 4.7. In addition reported that, fermentation was carried out by predominating flora of Pediococcus cerevisiae, Lactobacillus brevis, Lactobacillus plantarum and Lactobacillus fermentum and remained until the fermentation is terminated at $72 \mathrm{hr}$ [40]. Different scientists reported the role of yeasts at later stage of the fermentation. However, mould related information was not reported in the fermented batters. In contrast, Geta (2019), isolated the fungal species of different genera of Penicillium, Aspergillus, Rhizopus and Mucor species were isolated from spoiled teff injera [60].

Tilahun et al., (2018) isolate and identified the yeasts from fermenting teff dough and reported as Pichia fermentans, Pichia spp., Rhodotorula aurantiaca B, Pichia fluxuum, Candida humilis, Trichosporon beigelii B and, Cryptococcus albidus Var aerus [61]. Umeta \& Faulks, (1989) initially identified the action of the endogenous micro flora to produce sour dough. Also reported that, Lactic and acetic acids were the major organic acids produced $(90 \%)$ with seven other volatile fatty acids, propionic, isobutyric, n-butyric, isovaleric, n-valeric, isocaproic, n-caproic repre- senting less than 5\% [62].

\section{Scientific Studies reported on Preservation of Injera}

Usually on household level injera reported to be preserved for 2-3 days, again these duration may be depends on the processing, hygiene, variation in preparation practices, composition of the ingredients. However, very few preservation studies were carried by administration of chemical preservatives and the natural spices. Those reported studies are summarized in the following text.

Ashagrie and Abate, (2012) reported that, Aspergillus niger, Penicillium $s p$ and Rhizopus $s p$ found to be responsible in injera spoilage. Penicillium and Rhizopus are more dominant at the temperature of between 16$20^{\circ} \mathrm{C}$, while Aspergillus niger is more dominant at higher temperature of between $25-32^{\circ} \mathrm{C}$ [28]. Hassen, et al., (2018) also confirmed that at room temperature moulds took essential role in spoilage of injera and reported shelf life of 2-3 days [63].

Girma et al., (2013),was determined the effect of flax seed on the injera shelf life from 2 to 6 days, yeastmould (2.27 to $3.93 \mathrm{log} \mathrm{cfu} / \mathrm{g}$ ) and total aerobic plate counts (Not Detected to $3.77 \mathrm{log} \mathrm{cfu} / \mathrm{g}$ ) were lowest for 9\% flaxseed substitution and highest for the control injera [27].

Zewdu, (2009), studied the effect of $0.1 \%$ of benzoic acid/ sodium benzoate, $0.2 \%$ of potassium sorbate, $0.3 \%$ of calcium propionate and $0.2 \%$ blend of the flour on weight basis according to the Food and Drug Administration recommendations for 12 days of the storage. The effectiveness of preservation was ranked as sodium benzoate>benzoic acid $>$ potassium sorbate $>$ blend $>$ calcium propionate. The authors are reported that benzoates and benzoic acid are the most effective in preservation of the injera [64]. Similarly, Hassen and his co-workers determined the effects of benzoic acid (0.1\%), sodium benzoate $(0.1 \%)$, and potassium sorbate $(0.2 \%)$ and $1: 1: 1$ blend of the three $(0.2 \%)$ on injera shelf life. This researchers were confirmed that chemical preservatives ( 0.1 benzoic acid, $0.2 \%$ potassium sorbate, $0.1 \%$ sodium benzoate and $0.2 \%$ of the three preservatives) have capacity to extent the shelf-life of injera up to 10 days at room temperature [63].

In contrast Geta, (2019), evaluated the efficiency of locally available spices to enhance the shelf life and sensory attributes of teff injera. In the study used powder form of spice, hydro and ethanol extract of Nigella sativa seeds, Trigonella foenum seeds, Curcuma longa rhizomes, Carum at $2 \%$ concentration was used in the preservation of the injera. Shelf life of teff injera containing $2 \%$ powder, water extract and ethanol extract of $T$. foenum were 7, 7 and 9 days; C. sativum were 8,8 and 11 days; $N$. sativa were 7,8 and 10 days; $C$. copticum were 8, 7 and 9 days and C. longa were 5, 5 and 6 days reported, respectively [60]. 
Studies on the effect of processing methods on Quality of Injera

Hassen et al., (2018) reported the effect of the starter cultures (Lactobacillus plantarum + Saccharomyces cerevisiae) on rice-teff injera quality produced under controlled fermentation. Reported that best acceptability in softness, fluffiness, sponginess, slight sourness and eye size are attributes associated with quality of rice injera attributed to starter culture [65].

Wendy Attuquayefio, (2014) reported the effects of fermentation time and viscosity of batter on the elasticity and eye formation of injera and conformed that, both the factors were possess a significant effect on elasticity and eye formation in injera. Also reported that, injera from low or high viscosity batters produced fewer eyes on their surfaces. In the study concluded that, Injera batter with viscosity of 1.1 to 1.4 required for injera with more eyes. Moreover, addition of sodium metabisulphite (a reducing agent) in to batter reported a good elasticity and eye formation in injera this attributed to the contribution of the disulfide bonds in proteins to elasticity and eye formation [23].

Yetneberk, et al., (2005) evaluated the grain decortications and compositing with teff flour as methods to enhance the quality of injera made from tannin-containing and tannin-free red sorghums. From their research reported that, decortication and compositing are the both efficient ways to enhance the injera quality by both tannin-containing and tannin-free red sorghums. Also they were identified that, decortication positively influence the color and other quality properties of injera by decreasing the level of non-starch components of the grains. In the case of tannin-containing sorghum, decortication was reported for removal of tannins, improving injera fermentation. Same authors were reported that, mechanical abrasion is a best method to remove the tannins than the hand pounding to obtain injera with good sensory acceptable level [66]. Similarly, Seyoum et al., (2016) determined nutrient preservation, and the fate of iron-binding polyphenols during injera processing by improved tannin-free and high-tannin sorghum cultivars. In this study confirmed that, the high-tannin sorghum had significantly higher iron-binding polyphenols contents than the tannin-free sorghum. Decortication reported the loss of iron, calcium, iron-binding polyphenols, and tannin losses. In the same study reported that, sourdough fermentation processes reduced the ironbinding polyphenols and tannin levels in high-tannin sorghum. However, reported that, pre-soaking reduced the highest iron-binding polyphenols [67].

Assefa et al., (2018) studied the effect of mill type used in teff grinding on different properties of injera. In this study concluded that, differences in mill type used affected the color of the teff flour in contrast, the final color of the injera was not affected. The variation in injera sensory property and starch digestibility was reported and attributed to the variation in mill type used, where particle size distribution and the damaged starch levels were varied. The use of disc mill reported the tiny flour particle with high starch damage and reported a best sensory acceptability than that of blade mill and hammer mill. Blade mill reported to produce a larger flour particle size with lower rapid available glucose and digested starch [68].

Yoseph et al., (2018) determined the mechanical kneading and absit preparation on the quality of teff injera. They reported that, variation in kneading time and speed not affected free sugar, slow digestible starch, resistant starch, total starch and starch digestion rate index. This study also reported that, flavonoids, total phenolis and phytate contents depends on the kneading time-speed combinations. In addition, kneading process reported the overall acceptability of injera. In the same study confirmed that, absit preparation (water to fermented dough ratio) also found to affect the quality of teff injera. Same was confirmed by the study of Yoseph et al., (2018), where absit was prepared from $100 \mathrm{ml}$ of fermented dough and $900 \mathrm{ml}$ of water had the highest injera overall quality while, the lowest was observed in absit prepared from $300 \mathrm{ml}$ of fermented dough and 100 $\mathrm{ml}$ of water [69]. Dessalegn Abit (2018) reported the study on absit process factors dough level (10-20\%), agitation speed (200-300 rpm) and adding temperature (45$65^{\circ} \mathrm{C}$ ) on injera quality. From this study, concluded that, the optimum processing factors of absit by considering taste, texture, number of eyes, eye size, eye distribution, top \& bottom surface and overall acceptability were dough level of $11.06 \%$, agitation speed of 200rpm and temperature of $45{ }^{\circ} \mathrm{C}$ with a desirability of 0.91 [70].

\section{Scientific studies on the degradation of Anti-nutrition factors in injera}

Baye et al., (2014) reported variations in mineral absorption inhibitors by fermentation of injera. The highest Fe, $\mathrm{Zn}$ and $\mathrm{Ca}$ contents were found in teff-white sorghum injera. The lowest phytic acid: Fe and phytic acid: Zn molar ratios were found in barley-wheat and wheat-red sorghum injera. Although, ideal phytic acid: Fe molar ratios $(<0.4)$ were found in barley-wheat and wheat-red sorghum [71]. However, Baye et al., (2015) evaluated the effect of phytate removal, iron-binding polyphenols and dietary fibers on iron bio-accessibility in wheat-red sorghum and teff-white sorghum to make injera, by the application of exogenous enzymes. In this study confirmed that, the hydrolysis of dietary fibers improved iron bioaccessibility, suggesting the effect of the fiber is independent of phytate content. The researchers confirmed the improvement of iron bio-accessibility by applying a 
mix of phytase, cellulase, xylanase and Polyphenol oxidase enzymes [72].

Assefa et al., (2018) determined the mechanical mill type, kneading speed-time combinations on fermentation kinetics was investigated and phytate to mineral molar ratio ( $\mathrm{Fe}, \mathrm{Zn}$ and $\mathrm{Ca}$ ) of teff injera. In both milling and kneading levels reported maltose was the highest sugar concentration initially, than followed by glucose and fructose. As fermentation continued, a similar trend in maltose break down was reported in all studied mill types. However, for phytate/mineral molar ratio of the flours, reported significantly different both mills and kneading speed-time combinations [68].

Fischer et al., (2014) developed starter culture to substantially degrade phytic acid during injera preparation. Seventy-six isolates from 13 different teff fermentations were analyzed for phytase activity and out of 13 isolates 7 different species were detected as positive in a phytase screening assay. Lactobacillus buchneri strain MF58 and Pediococcus pentosaceus strain MF35 resulted in lowest remained phytic acid amounts after the fermentation $41 \%$ and $42 \%$, respectively, in comparison $59 \%$ of phytic acid remained in spontaneous fermentation. From this study concluded that, L. buchneri MF58 displaying the highest phytic acid degrading potential. Similarly, Shumoy et al., (2017) evaluated the in vitro dialysability of Fe and $\mathrm{Zn}$ in a back slop fermented injera. They reported that, traditional fermentation leads up to $49-66 \%$ of reduction in phytic acid. Molar ratios of Phytic acid: Fe and Phytic acid:Zn was decreased from 14 to 1 and 63 to 19, respectively, after $120 \mathrm{~h}$ of fermentation. The total soluble fractions of $\mathrm{Fe}$ and $\mathrm{Zn}$ reported in range of 11 and $38 \%$ and 11 and $29 \%$, respectively, after $120 \mathrm{~h}$ of fermentation [59]. Fischer et al., (2015) determined the effect of phytase enzyme on Fe bio-availability in injera. From this study reported that, iron absorption from traditional teff injera was low, suggesting that reducing the phytate content of teff injera by either cofortification with wheat or addition of purified phytase provides the more than doubled iron bioavailability from this Ethiopian staple food and would provide additional absorbable iron [73].

\section{Studies reported on fermentation kinetics}

Baye et al., (2013) reported the control of cereal blends, teff-white sorghum, barley-wheat and wheat-red sorghum, on fermentation kinetics in traditional fermentation of dough. In the study reported that, wheat-red sorghum and barley-wheat injera sourdough fermentations were characterized by a transient accumulation of glucose and maltose and a two-step fermentation process: lactic acid fermentation and alcoholic fermentation with ethanol as the major end product. Also concluded that, only transient accumulation of glucose was observed in teff-white sorghum, and equimolar concentrations of lactic acid and ethanol were produced simultaneously. Final $\alpha$-galactoside concentrations were reported low in all sourdoughs [74].

\section{Studies reported on bioactive compounds}

Shumoy et al., (2017) investigated the cause of fermentation on soluble and bound phenolic profiles and antioxidant potential of fermented injera for different intervals from 4 teff varieties of brown and white color. They concluded that, the contribution of soluble phenolic extracts to the total phenolic content ranged from 14 to $17 \%$ and $17-32 \%$, before and after fermentation, respectively. In phenolic acids, identified the gallic, protocatechuic, vanillic, syringic, p-coumaric, salicylic, ferulic acid, catechin and naringenin reported in both in the fermented and unfermented injera from Quncho and Zezew teff varieties. They confirmed that by $72 \mathrm{~h}$ of fermentation time, the majority of the phenolic compounds increased in the range of $42-1805 \%$ in soluble and decreased by $2-100 \%$ in bound extracts in both varieties. Finally, established that, fermentation for $72 \mathrm{~h}$ brown seed colored varieties (Zagurey and Zezew) showed superior in total phenolic and antioxidant contents compared to the white varieties (Quncho and Tsedey) [75]. Similarly, Shumoy et al., (2019) simulated static in vitro digestion of teff injera, sampled after different fermentation times, was performed to measure the dialyzable and soluble non-dialyzable total phenolic, total flavonoid contents, and their total antioxidants. The absolute total flavonoid contents fractions decreased as the fermentation increased from 0 to $120 \mathrm{~h}$. No clear pattern in the absolute radical scavenging capacity of the fractions was observed among different fermentation times [76].

Shumoy \& Raes, (2017) determined the in vitro starch digestibility of injera from seven teff varieties and estimated the glycemic index. The total starch, free glucose, apparent amylose, resistant, slowly digestible and rapidly digestible starches of the varieties ranged between 66 and 76, 1.8 and 2.4g/100g flour dry matter, 29 and 31\%, 17 and 68, 19 and 53,12 and 30g/100g starch, respectively. Finally, concluded that, teff injera classified as medium to high Glycimic Index (GI) foods, not to be considered as a proper food ingredient for diabetic people and patients in weight gain [77].

Boka, et al., (2013), reported the antioxidant properties of the injera prepared with white, brown and red teff variety and enriched with fenugreek. The anti-oxidant properties were observed in red teff while the lowest was shown in white teff. Total phenol content was higher in red teff (11.47 mg GAE/g) as compared to brown teff (9.72 mg GAE/g) and white teff ( $8.28 \mathrm{mg} / \mathrm{GAE} / \mathrm{g})$. Total flavonoids for white, brown and red teff were $1.03 \mathrm{mg} / \mathrm{g}$, $1.78 \mathrm{mg} / \mathrm{g}$ and $2.13 \mathrm{mg} / \mathrm{g}$, respectively. In antioxidant 
activities of injera decreased in the order of red teff injera $>$ brown teff injera $>$ white teff injera in the same processing conditions. This study concluded that, fermented teff injera (18 hrs of fermentation) had high antioxidant capacity than fully fermented teff injera (72 hrs of fermentation) among the same teff varieties [78].

\section{Conclusions}

Injera is a traditional Ethiopian staple diet for all the Ethiopians, still injera preparation is practicing in traditionally by using traditional approch. However, scientific community is conducted research on composite flour development for the better nutritional and sensory quality of the injera. In this area, researchers, studied the different teff, sorghum, barley varieties on nutritional and sensory properties and conformed that, verities are responsible for variation in the injera quality. The other major food ingredients was used in the composite flour development in the injera was, Lupine, Amaranth, Faba bean, Fenugreek, Maize, Rice, Cassava, Taro, Quinoa, Flaxseed, Kocho, All these ingredients types and their concentration reported to effected the nutritional, sensory and storage quality of injera. Different researchers were conformed the role of yeast and Lactic acid Bacteria in the fermentation process of the teff batter. Among the yeasts major reported were, Pichia, Candida, Saccharomyces species. In the case of the Lactic Acid Bacteria, Lactobacillus, Lactococcus, Leuconostoc, Pediococcus and Streptococcus species. In contrast, studies hardly find to determine the micro-organisms present in the injera after baking the batter. However, Injera usually preserved up to 3 days of the fermentation, and scientists are identified the fungi is the responsible for the injera spoilage like, Mucor, Rhizopus, Aspergillus species. Very limited studies are reported on the preservation of injera, reported the use of the chemical preservatives like Benzoic acid, Sodium Benzoate, Potassium Sorbate, Calcium Propionate. However, limited studies were reported on natural spices like Nigella sativa seeds, Trigonella foenum seeds, Curcuma longa rhizomes, Carum. However, by these studies reported maximum injera can preserve for 12 days with chemical preservatives. The researchers reported few studies on the reduction of the anti-nutritional factors like the phytic acid and confirmed the mineral availability in injera by fermentation process. In case of the quality properties of the injera, scientists were reported that, the injera quality was affected by the milling type and absit preparation methods. Finally, different studies reported on the availability of phenolic acids, like gallic, protocatechuic, vanillic, syringic, p-coumaric, salicylic, ferulic acid, catechin and naringenin in the teff and injera, concluded that, the teff varietal difference effected the phenolic acids type and composition.

\section{Acknowledgements}

Authors are grateful to the management of the Faculty of Chemical and Food Engineering, Bahir Dar University for continuous encouragement and facilitating requirements for complete this review.

\section{Authors' contributions}

The Idea was conceived by the NS and developed and guided by the SW. The data was collected and manuscript was prepared by NS. SW helped to develop review of the manuscript and procurement of the images. Finally, both the authors are reviewed the manuscript and accepted to communicate

Funding

Not Applicable

Availability of data and materials

All data collected during this review are included in this published article.

\section{Competing interests}

The authors declare that they have no competing interests.

Received: 14 January 2020 Accepted: 1 September 2020

Published online: 14 September 2020

\section{References}

1. Stewart RB, Getachew A. Investigations of the nature of Injera. Econ Bot. 1962;16(2):127-30

2. Girma T, Bultosa G, Bussa N. Effect of grain tef [Eragrostis tef (Zucc.) Trotter] flour substitution with flaxseed on quality and functionality of injera. Int J Food Sci Technol. 2013:48(2):350-6.

3. Abdullahi MD. Culture and Customs of Somalia. Greenwood Publishing Group; 2001.

4. Fanta SW, Neela S. A review on nutritional profile of the food from enset: A staple diet for more than 25 per cent population in Ethiopia. Nutr Food Sci. 2019;49(5):824-43.

5. Gebrekidan B and Belainesh GH. Sorghum injera preparations and quality parameters. In: Proceedings of the International Symposium on Sorghum Grain Quality, ICRISAT Center Patancheru, India held on 28-31 October 1981, p. 55-65.

6. Soni SK, Sandhu DK, Vilkhu KS, Kamra N. Microbiological studies on Dosa fermentation. Food Microbiol. 1986:3(1):45-53.

7. Ching PC, Shahar S, Haron H, Md Noh MF. Sugar Content of Selected Malaysian Desserts, Snacks and Cooked Foods Commonly Consumed by Malaysian Older Adults. J Sains Kesihat Malaysia. 2018;16(2):235-6.

8. Hailu MH, Nydal OJ, Kahsay MB, Tesfay AH. A direct solar fryer for injera baking application. In: Proceedings of ISES Solar World Congress 2017 - IEA SHC International Conference on Solar Heating and Cooling for Buildings and Industry, heald at Abu Dhabi, United Arab Emirates, on 29 October - 2 November 2017. p. 1475-85.

9. Annear C, Harris J. Cooking up the Culinary Nation or Savoring its Regions ? Teaching Food Studies in Vietnam. ASIA Network Exch. 2018;25(1):115-48.

10. Egorova KA. The Russian Cuisine in English Travel Guides to Russia. J Sib Fed Univ Humanit Soc Sci. 2013:4(2013 6):514-522.

11. Noskova A., Liliya Gazizova, Dunyasheva L, Estrella DO. The Problem of National and Cultural Semantics of Lexical Units in Spanish (On Material of Venezuelan And Nicaraguan Words Reflecting Forms of Work). Rev Publicando. 2017;102(13):24-5. Available from: http://www.tandfonline.com/ doi/abs/10.1080/14639947.2011.564813\%0A, https://doi.org/10.1080/ 15426432.2015.1080605\%0A, https://doi.org/10.1080/15426432.2015. 1080605\%0A, http://heinonline.org/HOL/Page?handle=hein.journals/abaj102 \&div $=144 \&$ start_page $=26 \&$ collectio .

12. Lim FKG. Hotels as sites of power: Tourism, status, and politics in Nepal Himalaya. J R Anthropol Inst. 2007;13(3):721-38.

13. Badi S, Pedersen B, Monowar L, Eggum BO. The nutritive value of new and traditional sorghum and millet foods from Sudan. Plant Foods Hum Nutr. 1990;40(1):5-19.

14. Mengesha MH. Chemical composition of teff (Eragrostis tef) compared with that of wheat, barley and grain sorghum. Econ Bot. 1966;20(3):268-73.

15. Bultosa G, Taylor J. Teff crop description and cultivation. Encyclopedia of grain science. Acadamic press, 2004. p. 281-290. 
16. Curtis KR, Entsminger JS, Cowee MW, Harris TR. Market potential for Nevada teff products, Techncal report No. UCED 2008/09-02; 2008.

17. Gebremariam MM, Zarnkow M, Becker T. Teff (Eragrostis tef) as a raw material for malting, brewing and manufacturing of gluten-free foods and beverages: a review. J Food Sci Technol. 2014;51(11):2881-95.

18. Abebe Y, Bogalea A, Hambidge KM, J. Stoecker B, Bailey K, S. Gibson R. Phytate, zinc, iron and calcium content of selected raw and prepared foods consumed in rural Sidama, Southern Ethiopia, and implications for bioavailability. J Food Compos Anal. 2007; 20(1):161-161. on.

19. USDA. Teff nutritional composition. USDA Food Nutriti al Data base. 2019. Available from: https://fdc.nal.usda.gov/fdc-app.html\#/food-details/361081/ nutrients. Acessed 30 Dec 2019.

20. USDA. Injera (American-style Ethiopian bread). USDA Food Nutriti al Data base. 2019. https://fdc.nal.usda.gov/fdc-app.html\#/food-details/339705/ nutrients. Acessed 30 Dec 2019

21. Kebede B. Food People Eat : the Energy Economics of Injera and Wot. Ethiop Econ Struct Probl Policy Issues. 1992;22-6.

22. Zegeye A. Acceptability of injera with stewed chicken. Food Qual Prefer. 1997;8(4):293-5

23. Wendy Darling Attuquayefio. Influence of processing parameters on eye size and elasticity of tef-based injera. The Pennsylvania State University; 2014.

24. House L R. Sorghum and Millets: history, Taxonomy, and Distribution. In: David Dendy AV, editor. Sorghum and millets: chemistry and Technology. American Association of Cereal Chemists press, St. Paul, Minnesota, USA. 1995.p.1-10.

25. Harry Kloman (2013). Feasting with the Ancients, In Ethiopian food Mesob across America, A companion site to the book. Available from: https:// ethiopianfood.wordpress.com/2013/07/01/feasting-with-the-ancients/. Accessed 22 August 2020.

26. Marian (2011). Spider web unite, my volunteer experience in Ethiopia, https://spiderwebsunite.wordpress.com/2011/06/. Accessed 22 August 2020.

27. Girma T, Bultosa G, Bussa N. Effect of Grain Tef (Eragrostis tef (Zucc.) Trotter) Flour Substitutions with Flaxseed on Mineral Content, Antioxidant Activity, Phytic Acid Content and Microbial Quality of Injera Tewodros. Sci Technol arts Reserch J. 2013;2(3):51-8.

28. Ashagrie Z, Abate D. Improvement of Injera Shelf Life Through the Use of chemical preservatives. Afr J Food Agric Nutr Dev. 2012;12(5):6409-23.

29. Steinkraus K. Handbook of Indigenous Fermented Foods, Revised and Expanded. CRC Press, 1995. 792 p.

30. Ashenafi M. Microbial flora and some chemical properties of ersho, a starter for teff (Eragrostis tef) fermentation. World J Microbiol Biotechnol. 1994;10(1): 69-73.

31. Abraha A, Uhlen AK, Abay F, Sahlstrøm S, Bjørnstad Å. Genetic variation in barley Enables a high quality injera, the Ethiopian staple flat bread, comparable to tef. Crop Sci. 2013;53(5):2040-50.

32. Abiyu HT, Woldegiorgis AZHG. Preparation of injera from pre-fermented flour: Nutritional and sensory quality. Int J Sci Innov Discov. 2013;3(1):165-75.

33. Girma M, Gashe BA, Lakew B. The effect of fermentation on the growth and survival of Salmonella typhimurium, Staphylococcus aureus, Bacillus cereus and Pseudomonas aeruginosa in fermenting tef (Eragrostis tef). MIRCEN J Appl Microbiol Biotech. 1989;5(1):61-6.

34. Parker ML, Umeta M, Faulks RM. The contribution of flour components to the structure of injera, an Ethiopian fermented bread made from tef (Eragrostis tef). J Cereal Sci. 1989;10(2):93-104.

35. Mihrete $Y$. The mineral content and sensory properties of Injera made from the faba bean, sorghum and tef flour blends. Int J Nutr. 2019:4(2):1-11.

36. Desiye A, Abegaz K, Negera E. The Microbiology of Teff (Eragrostis tef) Enjera. Sch J Res Agric Biol. 2017;2(2):115-20

37. Beruk BD, Fasil TD. Effect of Blending Ratio on Proximate Composition, Physico-Chemical Property, and Sensory Acceptability of Injera Produced from Red Tef (Eragrostis tef) and Cassava (Manihot esculenta). Food Sci Qual Mangement. 2017;68:6-10.

38. Mihrete B. The Effect of Blending Ratio of Tef [Eragrostis tef (Zucc) Trotter], Sorghum (Sorghum bicolor (L.) Moench) and Faba Bean (Vicia faba) and Fermentation Time on Chemical Composition of Injera. J Nutr Food Sci. 2017;07(02):1-7.

39. Chemeda AS, Bussa NF. Effect of Processing Methods on Nutritional and Anti-nutritional Value of Amaranth Grain and Potential Future Application of Amaranth Grain in Injera Making. Int J Fermented Foods. 2018;7(1):11-20.
40. Gashe BA. Involvement of Lactic Acid Bacteria in the Fermentation of TEF (Eragrosfis tef), an Ethiopian Fermented Food. J Food Sci. 1985;50(3):800-1.

41. Jones R, Diehl JC, Simons L, Verwaal M. The development of an energy efficient electric Mitad for baking injeras in Ethiopia. In: Proceedings of the 25th Domestic Use of Energy Conference: Towards Sustainable Energy Solutions for the Developing World, Cape Town, South Africa. 2017. p. 75-82.

42. Adem KD, Ambie DA. A review of injera baking technologies in ethiopia: challenges and gaps. Energy Sustain Dev. 2017;41(1):61-80.

43. Yegrem L. Evaluation of nutritional composition and sensory acceptability of tef (Eragrostis Tef (Zucc.) Trotter) complemented with lupine (Lupinus Spp.) injera. Haramaya University, Ethiopia, 2019.

44. Woldemariam F, Mohammed A, Fikre Teferra T, Gebremedhin $\mathrm{H}$. Optimization of amaranths-teff-barley flour blending ratios for better nutritional and sensory acceptability of injera. Cogent Food Agric. 2019; 5(1)

45. Godebo DD, Dessalegn E, Niguse G. Nutritional Composition, Microbial Load and Sensory Properties of Fenugreek (Trigonella foenum-graecum L.) Flour Substituted Injera. J Food Process Technol. 2019;10(7):1-7.

46. Godebo DD, Dessalegn E, Nigusse G. Evaluation of Phytochemical Content and Antioxidant Capacity of Processed Fenugreek (Trigonella foenum-graecu L.) Flour Substituted Injera. Food Sci Qual Manag. 2019;91:9-18.

47. Tamene A, Kariluoto S, Baye K, Humblot C. Quantification of folate in the main steps of traditional processing of tef injera, a cereal based fermented staple food. J Cereal Sci. 2019;87(2):225-30.

48. Cherie Z, Ziegler GR, Fekadu Gemede H, Zewdu WA. Optimization and modeling of teff-maize-rice based formulation by simplex lattice mixture design for the preparation of brighter and acceptable injera. Cogent Food Agric. 2018;4(1):1-19.

49. Agza B, Bekele R, Shiferaw L. Quinoa (Chenopodium quinoa, Wild.): As a potential ingredient of injera in Ethiopia. J. Cereal Sci. 2018;82(1):170-4.

50. Abraha A, Abay F. Effect of different cereal blends on the quality of Injera a staple food in the highlands of Ethiopia. Momona Ethiop J Sci. 2017;9(2): 232.

51. Ghebrehiwot HM, Shimelis HA, Kirkman KP, Laing MD, Mabhaudhi T. Nutritional and sensory evaluation of injera prepared from tef and Eragrostis curvula (Schrad.) nees. flours with sorghum blends. Front Plant Sci. 2016;7(7):1-8.

52. Abera A, Milkesa M, Gebremedhin H. Injera Preparation from Taro ( Colocasia esculenta) and Teff ( Eragrostis tef) Flour. Int J Sci Basic Appl Res. 2016;30(1):196-204.

53. Mohammed NA, Ahmed IAM, Babiker EE. Nutritional evaluation of sorghum flour (Sorghum bicolor L. Moench) during processing of injera. World Acad Sci Eng Technol. 2011;75:72-6.

54. Yetneberk S, De Kock HL, Rooney LW, Taylor JRN. Effects of Sorghum Cultivar on Injera Quality. Cereal Chem. 2004;81(3):314-21.

55. Zewdie S, Urga K, Nigatu A. Co-Fermentation of Kocho with Barley for an Improved injera. SINET Ethiop J Sci. 1997;20(2):261-70.

56. Cherinet $\mathrm{H}$. View of composite flour development for injera. Heal Dev Ethiop J. 1993;7(2):71-7.

57. Tadesse BT, Abera AB, Tefera AT, Muleta D, Alemu ZT, Wessel G. Molecular Characterization of Fermenting Yeast Species from Fermented Teff Dough during Preparation of Injera Using ITS DNA Sequence. Int J Food Sci. 2019; Article ID 1291863.

58. Desiye A, Abegaz K. Isolation, characterization and identification of lactic acid bacteria and yeast involved in fermentation of teff (Eragrostis tef) batter. Adv Res Biol Sci. 2013;1:36-44.

59. Fischer MM, Egli IM, Aeberli I, Hurrell RF, Meile L. Phytic acid degrading lactic acid bacteria in tef-injera fermentation. Int J Food Microbiol. 2014; 190(1):54-60.

60. Geta K. Efficiency of Locally Available Spices to Improve Shelf Life and Sensory Attributes of Teff Injera. World Sci News. 2019;136(9):159-72.

61. Tilahun B, KAssaye E, Abera G, Tesfaye A, Muleta D, Bahiru A, et al. View of Biolog Identification of Fermenting Yeasts from Fermented Teff (Eragrostis teff (Zucc.)) Dough. Asian J Biol. 2018;5(4):1-7.

62. Umeta M, Faulks RM. Lactic acid and volatile (C2-C6) fatty acid production in the fermentation and baking of tef (Eragrostis tef). J Cereal Sci. 1989;9(1): 91-5.

63. Hassen Y, Mukisa IM, Kurabachew $H$. The Effect of Selected Chemical Preservatives and Starter Cultures on the Sensory Characteristics and Shelf Life of Rice Injera. J Bioprocess Biotech. 2018;08(01):1-7.

64. Zewdu A. Improvement of shelflife of injera using chemical preservatives. Addis Ababa University, Ethiopia. 2009. 
65. Hassen Y, Mukisa IM, Kurabachew H, DEsalegn BB. Evaluation of Yeast and Lactic Acid Bacteria Starter Cultures for the Production of Rice Injera. J Food Process Technol. 2018;09(03):1000721.

66. Yetneberk S, Rooney LW, Taylor JRN. Improving the quality of sorghum injera by decortication and compositing with tef. J Sci Food Agric. 2005: 85(8):1252-8.

67. Seyoum Y, Retta N, Baye K. Nutrient retention and fate of iron-binding phenolic compounds during the injera processing of tannin-free and hightannin sorghum. J Sci Food Agric. 2016;96(5):1541-7.

68. Assefa YL, Emire SA, Abebe W, Ronda F. Effect of Mill Type and Mechanical Kneading Conditions on Fermentation Kinetics of Tef Dough During Injera making and Phytate to Mineral Molar Ratio of Injera. Res \& Rev: J Food Sci and Tech. 2018;7(2):9-19.

69. Yoseph LA, Shimelis AE, Workineh A, Marina V, Felicidad R. The effect of mechanical kneading and absit preparation on tef injera quality. Afr J Food Sci. 2018;12(10):246-53.

70. Abit D. Optimization of Absit process factors to improve the physicochemical and sensory quality of Teff [ Eragrostis tef (Zucc.) Trotter ] Injera. Addis Ababa University, Ethiopia; 2018.

71. Baye K, Mouquet-Rivier C, Icard-Vernière C, Picq C, Guyot JP. Changes in mineral absorption inhibitors consequent to fermentation of Ethiopian injera: Implications for predicted iron bioavailability and bioaccessibility. Int Food Sci Technol. 2014;49(1):174-80.

72. Baye K, Guyot J-P, Icard-Vernière C, Rochette I, Mouquet-Rivier C. Enzymatic degradation of phytate, polyphenols and dietary fibers in ethiopian injera flours:Effect on iron Bioaccessibility. Food Chem. 2015;174(1):60-7.

73. Fischer M, Egli I, Aeberli I, Zimmermann M, Hurrell R. Strategies to Enhance Iron Absorption from Tef-injera in Young Women. Eur J Nutr Food Saf. 2015; 5(5):1169-70.

74. Baye K, Rivier CM, Verniere $\mathrm{Cl}$, Rochette I. Influence of Flour blend composition on fermentation kinetics and fermentation phytate hydrolysis of sordough used to make injera. Food Chem. 2013;138:430-6.

75. Shumoy H, Gabaza M, Vandevelde J, Raes K. Soluble and bound phenolic contents and antioxidant capacity of tef injera as affected by traditional fermentation. J Food Compos Anal. 2017:58(1):52-9.

76. Shumoy H, Gabaza M, Vandevelde J, Raes K. Impact of fermentation on invitro bioaccessibility of phenolic compounds of tef injera. LWT Food Sci Technol. 2019;99:313-8.

77. Shumoy H, Raes K. In vitri starch hydrolysis and estimated glycemic index of tef porridge and injera. Food Chem. 2017;299:381-7.

78. Boka B, Woldegiorgis AZ, Haki GD. Antioxidant Properties of Ethiopian Traditional Bread (Injera) as Affected by Processing Techniques an d Tef Grain (Eragrostis tef (Zucc.)) Varieties. Can Chem Trans. 2013;1(1):7-24.

\section{Publisher's Note}

Springer Nature remains neutral with regard to jurisdictional claims in published maps and institutional affiliations.

Ready to submit your research? Choose BMC and benefit from:

- fast, convenient online submission

- thorough peer review by experienced researchers in your field

- rapid publication on acceptance

- support for research data, including large and complex data types

- gold Open Access which fosters wider collaboration and increased citations

- maximum visibility for your research: over $100 \mathrm{M}$ website views per year

At $\mathrm{BMC}$, research is always in progress.

Learn more biomedcentral.com/submissions 